\title{
On the relative role of sea salt cloud condensation nuclei $(\mathbf{C C N})$
}

\author{
James G. Hudson • Stephen Noble • Vandana Jha
}

Received: 11 May 2011 / Accepted: 18 November 2011 /

Published online: 4 December 2011

(C) The Author(s) 2011. This article is published with open access at Springerlink.com

\begin{abstract}
Contrasts between cloud condensation nuclei $(\mathrm{CCN})$ spectral volatility (thermal fractionation) measurements in two aircraft field projects provide insight into the relative contribution of sea salt. During the much more cloudy Rain in Cumulus over the Ocean (RICO) project there was a high correlation coefficient (R) between refractory (non-volatile) CCN concentrations $\left(\mathrm{N}_{\mathrm{CCN}}\right)$ and horizontal wind speed $(\mathrm{U})$, especially for low supersaturation (S) $\mathrm{N}_{\mathrm{CCN}}$, whereas this $\mathrm{R}$ was significantly lower in the nearly cloud free Pacific Aerosol Sulfur Experiment (PASE) project. Volatile $\mathrm{N}_{\mathrm{CCN}}$ at all $\mathrm{S}$ were uncorrelated with U. Ambient particle concentrations over a broad range of large sizes displayed consistently high $\mathrm{R}$ with $\mathrm{U}$ in both projects that was similar to the R of refractory $\mathrm{N}_{\mathrm{CCN}}$ with $\mathrm{U}$ in RICO. The size range of this high R extended down to $0.2 \mu \mathrm{m}$ in RICO but only down to $9 \mu \mathrm{m}$ in PASE. In both projects particle concentrations smaller than these respective sizes were highly correlated with $\mathrm{N}_{\mathrm{CCN}}$, at all $\mathrm{S}$ in PASE, but mainly with $\mathrm{N}_{\mathrm{CCN}}$ at high $\mathrm{S}$ in RICO. In each project $\mathrm{N}_{\mathrm{CCN}}$ at all $S$ was uncorrelated with all ambient particle concentrations larger than these same respective sizes. $\mathrm{N}_{\mathrm{CCN}}$ at all $\mathrm{S}$ was also uncorrelated with $\mathrm{U}$ in both projects. The contrast in cloudiness between the two projects was responsible for many of the differences noted between the two projects. The results indicate that the effects of clouds on $\mathrm{N}_{\mathrm{CCN}}$ play a major role in the relative influence of sea salt on $\mathrm{N}_{\mathrm{CCN}}$ and ultimately on climate. Sea salt is a minor component of maritime CCN except at high wind speeds especially at low S.
\end{abstract}

Keywords Cloud condensation nuclei $\cdot$ Aerosol $\cdot$ Cloud microphysics $\cdot$ Sea salt

\section{Introduction}

The most important question about the largest climate forcing uncertainty, the indirect aerosol effect (IAE) (Alley et al. 2007), is the relative attribution between anthropogenic and natural cloud condensation nuclei $(\mathrm{CCN})$. The main problem with this pursuit is that natural $\mathrm{CCN}$ sources are less understood than unnatural sources. The best understood

J. G. Hudson $(\bowtie) \cdot$ S. Noble $\cdot$ V. Jha

Desert Research Institute, Nevada System of Higher Education, Reno, NV 89512-1095, USA

e-mail: hudson@dri.edu 
natural $\mathrm{CCN}$ source is the mechanical action of wind on the sea surface, which pushes sea salt aerosol into the atmosphere. This has long been known to be a prolific source of giant nuclei (GN > $1 \mu \mathrm{m}$; e.g., Woodcock 1952). The high correlation between GN and horizontal wind speed (U) over the ocean is well established (e.g., Colon-Robles et al. 2006, hereafter CR6). However, for the much smaller and more numerous CCN Twomey (1968, 1971) and Hudson and Da (1996; hereafter HD6) demonstrated that the major constituent of sea salt $(\mathrm{NaCl})$ is only a minor component of $\mathrm{CCN}$ number concentrations $\left(\mathrm{N}_{\mathrm{CCN}}\right)$ even over the ocean. On the other hand, O'Dowd et al. (1993; hereafter O3), O'Dowd and Smith (1993; hereafter OS3), and Murphy et al. (1998) indicate that a larger proportion of $\mathrm{CCN}$ originate at the ocean surface. Clarke et al. (2006) even presented evidence of significant submicrometer $\mathrm{NaCl}$ aerosol. An important question is whether wind-produced ocean wave action generates enough small soluble particles to account for a significant fraction of observed $\mathrm{N}_{\mathrm{CCN}}$ and thus cloud droplet concentrations $\left(\mathrm{N}_{\mathrm{c}}\right)$. This continues to be a matter of controversy that is of great importance for understanding IAE (e.g., O’Dowd et al. 1997; Yoon and Brimblecombe 2002; Pierce and Adams 2006).

One of the best methods to discriminate the major constituent of sea salt aerosol, $\mathrm{NaCl}$, is volatility or thermal fractionation. Compared to most other common soluble atmospheric aerosol materials mainly sulfate, $\mathrm{NaCl}$ has a considerably higher vaporization temperature of more than $600 \mathrm{C}$ compared to approximately $200 \mathrm{C}$ for most sulfates (e.g., O3; HD6). This was the basis for the conclusions of Twomey $(1968,1971)$ and HD6 of the small NaCl contribution to $\mathrm{N}_{\mathrm{CCN}}$; i.e., they found that approximately $90 \%$ of $\mathrm{CCN}$ evaporated at temperatures well below $600 \mathrm{C}$ and thus could not be composed of $\mathrm{NaCl}$.

Here we present detailed CCN spectral volatility measurements from two aircraft field projects in contrasting marine air masses along with wind speed (U) and ambient particle size measurements. All presented measurements were made from the NCAR C-130 airplane flying within the marine boundary layer at altitudes less than $100 \mathrm{~m}$ during the Rain in Cumulus over the Ocean (RICO) project and the Pacific Aerosol Sulfur Experiment (PASE). RICO (Rauber et al. 2007) took place in the northeast Caribbean in DecemberJanuary, 2004-05 based on the island of Antigua $\left(18^{\circ} \mathrm{N}, 61^{\circ} \mathrm{W}\right)$. PASE occurred in the central Pacific in August-September 2007 (Conley et al. 2009; Faloona et al. 2010) based on Christmas Island (Kiritimati, Kiribati; $2^{\circ} \mathrm{N}, 157^{\circ} \mathrm{W} ; 2140 \mathrm{~km}$ directly south of Honolulu, $\mathrm{HI})$. The PASE location was chosen for its remoteness from anthropogenic sources and for the lack of clouds, which would complicate the atmospheric chemistry goals of the project. The season for PASE was also chosen for minimal cloudiness. RICO on the other hand was a cloud and precipitation investigation. In spite of the more remote location of PASE, Table 1 shows much higher $\mathrm{N}_{\mathrm{CCN}}$ of PASE compared to RICO, which Hudson and Noble 2009 (hereafter HN9) attributed to the greater cloudiness of RICO. HN9 also point out that back trajectories indicated that the air encountered throughout PASE probably come from South America. Average U and relative humidities $(\mathrm{RH})$ were similar for the two projects. The slightly lower U and RH of PASE were at least partly due to the slightly lower overall altitudes of the PASE measurements (50-100 m versus $100 \mathrm{~m})$.

\section{Results}

The black symbols in Fig. 1a expand the relationship between GN concentrations $\left(\mathrm{N}_{\mathrm{GN}}\right)$ and $U$ that was presented for RICO by CR6. This method used ambient boundary layer total PMS Forward Scattering Spectrometer Probe (FSSP) particle concentrations (diameter $2.35-46 \mu \mathrm{m}$ ) measured at $100 \mathrm{~m}$ altitude (within the boundary layer well below the bases of 
Table 1 Average and standard deviation of CCN concentrations at $1 \% \mathrm{~S}\left(\mathrm{~N}_{1 \%}\right)$, wind speed (U) and relative humidity (RH) at altitudes less than $100 \mathrm{~m}$ for all flights and for only the flights with volatility measurements

\begin{tabular}{lllll}
\hline & flights & $\mathrm{N}_{1 \%}$ & $\mathrm{U}$ & $\mathrm{RH}$ \\
\hline RICO & 17 total & $106 \pm 36$ & $9.2 \pm 2.1$ & $75.6 \pm 3.0$ \\
& 12 volatile & $111 \pm 37$ & $9.8 \pm 2.1$ & $76.3 \pm 3.0$ \\
PASE & 13 total & $302 \pm 63$ & $8.3 \pm 1.4$ & $75.4 \pm 4.0$ \\
& 10 volatile & $288 \pm 50$ & $8.6 \pm 1.3$ & $74.4 \pm 3.1$ \\
\hline
\end{tabular}

the clouds) to estimate $\mathrm{N}_{\mathrm{GN}}$. Figure 1a displays the same correlation coefficient (R) for total cumulative FSSP concentrations $(>2.35 \mu \mathrm{m})$ with $\mathrm{U}$ that was displayed by CR6 $(R=0.87)$. Figure 1a extends this relationship to cumulative FSSP concentrations at all sizes. All R values in Fig. 1a considered 26 data points corresponding to measurements averaged over 26 different $100 \mathrm{~m}$ altitude half hour flight circles. There were two of these for all but one of the 17 RICO flights that are considered here. Only 14 flights are included in the data set displayed in Fig. 1a because the Passive Cavity Aerosol Spectrometer Probe (PCASP) instrument was inoperative for 3 RICO flights. Only one measurement circle was flown for one of these flights and for one other flight complete measurements were available for only one of the circles. Nevertheless, nearly identical $\mathrm{R}$ values and $\mathrm{R}$ patterns are found for the FSSP data when all 32 or 33 available $100 \mathrm{~m}$ flight circles are included. Moreover, the R values are virtually identical when differential concentrations within the various FSSP size cells are considered. The decrease of the $\mathrm{R}$ values for $\mathrm{U}$ with concentrations at large sizes in Fig. 1a is mainly due to lack of statistics as concentrations went to zero for many of the

Fig. 1 Correlation coefficients (R) between average cumulative ambient particle concentrations larger than various threshold sizes with average wind speeds (U) and with average $\mathrm{CCN}$ concentrations at $1 \%$ supersaturation $(\mathrm{S})\left(\mathrm{N}_{1 \%}\right)$. All RICO data at $100 \mathrm{~m}$ altitude. PASE data at altitudes 50-100 m. Each PCASP concentration includes each total FSSP concentration. (a) 26 data points corresponding to averages over 26 half hour circles during 14 RICO flights. (b) Averages over 8 PASE flights are considered

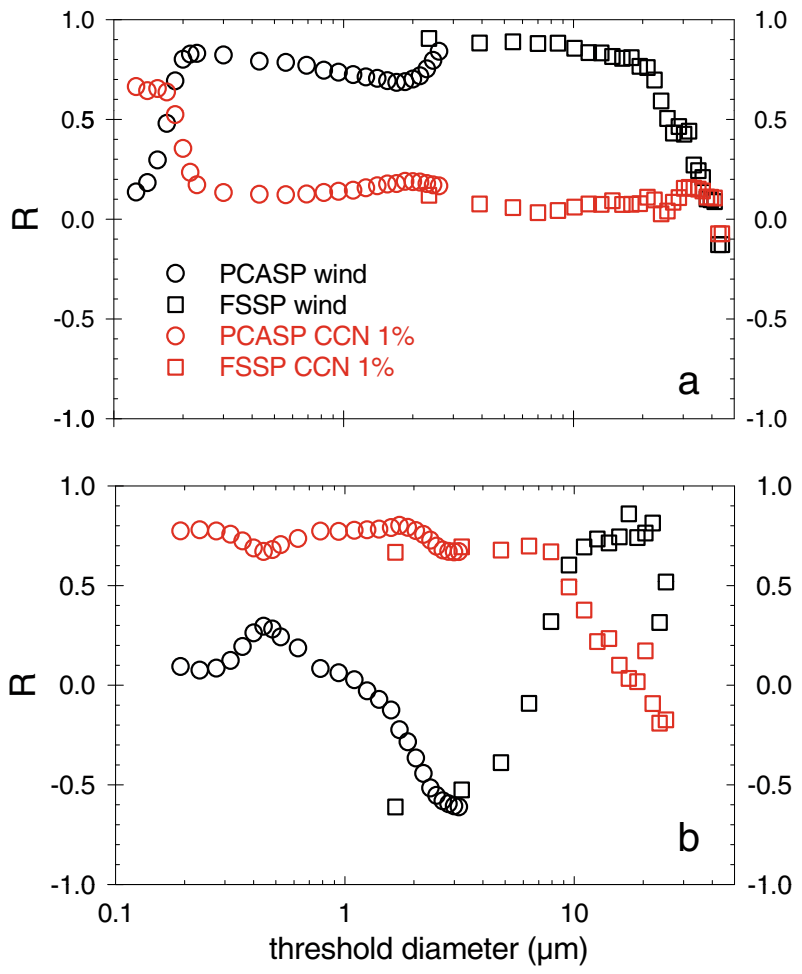


flight circles. The consistent values of this $\mathrm{R}$ up to sizes of 10 and even $20 \mu \mathrm{m}$ verifies the argument by CR6 that the lower particle concentrations at larger sizes are proportional to total FSSP concentrations; i.e., $\mathrm{N}_{\mathrm{GN}}$ are in the same proportions at all GN sizes.

Figure 1a also extends the relationship between $U$ and particle concentrations to smaller sizes by displaying the $\mathrm{R}$ pattern for the adjacent particle size range measured by the PCASP $(0.125-2.60 \mu \mathrm{m}$ diameter). The uniformly high $\mathrm{R}$ down to $0.2 \mu \mathrm{m}$ indicates that particles over the entire size range from $0.2-20 \mu \mathrm{m}$ were in similar proportions among the RICO flights. Again the $\mathrm{R}$ values and $\mathrm{R}$ pattern were nearly identical when differential PCASP particle concentrations were considered.

Figure 1a also displays the $\mathrm{R}$ pattern for $\mathrm{CCN}$ concentrations $\left(\mathrm{N}_{\mathrm{CCN}}\right.$ here at $1 \% \mathrm{~S}$ so $\left.\mathrm{N}_{1 \%}\right)$ measured by the DRI CCN spectrometers (Hudson 1989) as presented by Hudson and Mishra (2007) and Hudson et al. (2009; hereafter H9) with cumulative PCASP and FSSP concentrations larger than the various threshold sizes. Only the smallest particles measured by the PCASP show a correlation with $\mathrm{N}_{1 \%}$, and this is the only ambient particle size range that is uncorrelated with U. Again the same R pattern is observed for differential PCASP and FSSP particle concentrations and for the greater number of flights available for FSSP data.

Figure $1 \mathrm{~b}$ shows these same R patterns for PASE; all measurements at altitudes between 50 and $100 \mathrm{~m}$ (boundary layer), which provided more than $1 \mathrm{~h}$ of data for each flight. CCN measurements were made with the same DRI instruments and were presented by HN9 for PASE. In a broad sense the PASE figure shows similar R patterns to those of RICO-large particles correlated with $\mathrm{U}$ but not with $\mathrm{N}_{1 \%}$ and small particles correlated with $\mathrm{N}_{1 \%}$ but not with U-except that the size marking the transitions of both $\mathrm{R}$ patterns is very much larger, $9 \mu \mathrm{m}$ compared to $0.2 \mu \mathrm{m}$ for RICO. Figure $1 \mathrm{~b}$ is limited to considerations of flight averages over only the 8 PASE flights that had PCASP data. However, as in RICO the FSSP R patterns are nearly identical when all 12 or 13 of the PASE flights with appropriate data are considered. Furthermore, as with RICO the R patterns are also almost identical when differential particle concentrations are considered. As in RICO the drop off of $\mathrm{R}$ for $\mathrm{U}$ with particle sizes greater than $15 \mu \mathrm{m}$ is due to statistical limits (zero concentrations for some flights).

Since all particle measurements were made at ambient conditions outside of the airplane, the measured sizes, and thus concentrations at those sizes, were also a function of the ambient RH. Table 1 shows that the mean RH of the two projects was so similar that on average the differences of the dry particle sizes corresponding to the mean ambient sizes were no more than $2 \%$ between the two projects. This estimate uses equation 15 of Gerber (1988) to relate equilibrium size as a function of RH to dry particle size for the two most likely water soluble particle compositions, ammonium sulfate and sodium chloride $(\mathrm{NaCl})$. The differences between the dry particle sizes and the measured ambient particle sizes that are presented varied from a factor of 1.5-2.35; these factors are larger for $\mathrm{NaCl}$, higher $\mathrm{RH}$, or larger sizes. The differences in these factors (measured sizes to dry particle sizes) for the most extreme differences in mean RH among the flights/cases of each project were $20 \%$. However, the correlations between $\mathrm{RH}$ and $\mathrm{U}$ were slightly negative $(R=-0.34$ for RICO and -0.44 for PASE). Since measured ambient particle sizes, and thus also cumulative particle concentrations, are positively related to $\mathrm{RH}$, the negative $\mathrm{R}$ between $\mathrm{U}$ and $\mathrm{RH}$ indicates that the dry particle concentrations probably had higher $\mathrm{R}$ with $\mathrm{U}$ than the ambient particle concentration $\mathrm{R}$ values presented in Fig. 1. Indeed higher $\mathrm{R}$ values were found between $U$ and particle concentrations that were inversely normalized to ambient RH. In other words the differences in RH, on the whole, tended to make the R of measured particle concentrations with $\mathrm{U}$ lower than the R values of dry particle concentrations with $\mathrm{U}$.

Figure 2 shows that $\mathrm{N}_{\mathrm{CCN}}$ at all $\mathrm{S}$ are uncorrelated with $\mathrm{U}$ in both projects. Figure $3 \mathrm{a}$ shows that in RICO, although high $\mathrm{S} \mathrm{CCN}\left(\mathrm{N}_{1 \%}\right)$ are not correlated with large particles, 


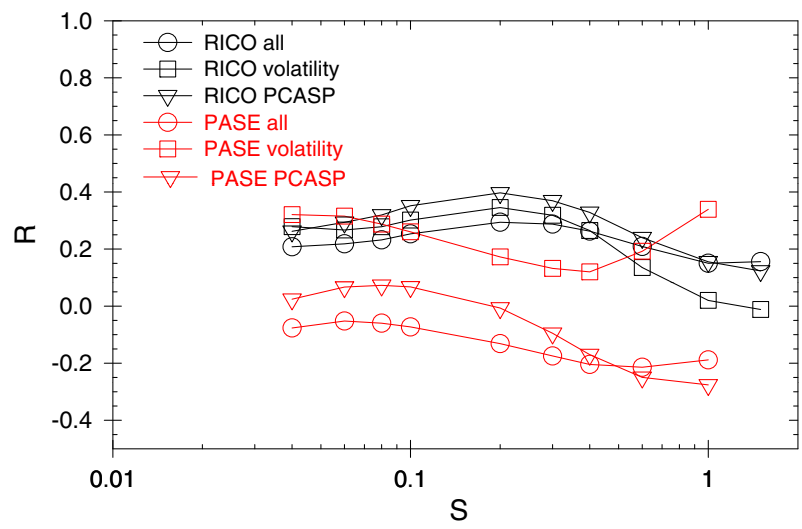

Fig. 2 Correlation coefficients $(\mathrm{R})$ between average $\mathrm{CCN}$ concentrations $\left(\mathrm{N}_{\mathrm{CCN}}\right)$ at various $\mathrm{S}$ with average horizontal wind speeds (U) for RICO and PASE. All RICO data at $100 \mathrm{~m}$ altitude. PASE data at altitudes 50$100 \mathrm{~m}$. All for RICO considers averages over 32 half hour circles during 17 flights, RICO volatility considers only the 24 circles that also had volatility measurements, RICO PCASP considers only the 26 circles that also had PCASP data. All for PASE considers averages over 12 flights, PASE volatility considers only the 8 flights that also had volatility measurements, PASE PCASP considers only the 8 flights that also had PCASP data

lower $\mathrm{S} \mathrm{N}_{\mathrm{CCN}}$ are better correlated with concentrations of large ambient particles and this correlation is progressively higher for lower $\mathrm{S} \mathrm{N}_{\mathrm{CCN}}$. In the same vein the high $\mathrm{R}$ values for $\mathrm{N}_{1 \%}$ with small particles are progressively lower for lower $\mathrm{S} \mathrm{N}_{\mathrm{CCN}}$ in RICO. These results are in accord with the fact that lower S CCN are generally larger particles, especially if the

Fig. 3 As Fig. 1 for cumulative $\mathrm{N}_{\mathrm{CCN}}$ at various $\mathrm{S}$ with cumulative PCASP and FSSP concentrations; a RICO; b PASE
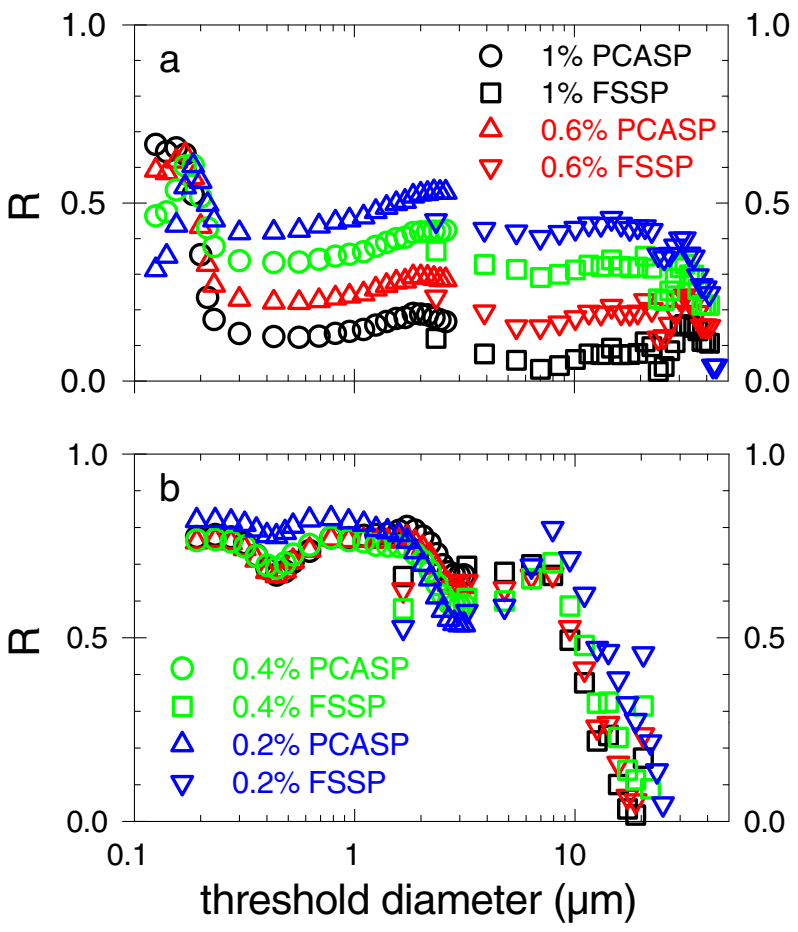
compositions are similar, i.e., if they are $\mathrm{NaCl}$. Nonetheless, none of the $\mathrm{N}_{\mathrm{CCN}}$ of RICO are as well correlated with any ambient particle concentrations as are any of the $\mathrm{N}_{\mathrm{CCN}}$ of PASE (Fig. 3b), which are all similarly well correlated with ambient particle concentrations up to $9 \mu \mathrm{m}$.

During twelve RICO flights and eight PASE flights CCN volatility measurements were made by periodically passing sample through an oven that was heated to various temperatures (HD6). The procedure was to alternate between direct ambient sampling and high temperature processed (HTP) sampling on time scales of 1-2 min. Average concentrations during each HTP measurement were then compared with the average of ambient measurements immediately before and after each HTP measurement to determine the refractive (surviving, non-volatile) fraction of $\mathrm{N}_{\mathrm{CCN}}$ as the temperature of the oven was changed over periods of a few minutes. The uniformity of boundary layer $\mathrm{N}_{\mathrm{CCN}}$ during RICO (H9) and PASE (HN9) supported this procedure. Figure 4 shows examples of volatility measurements during RICO and PASE.

HTP measurements were usually done at or very close to temperatures of 300,400 , and 500C. Since measurements at higher HTP temperatures were available for only 5 RICO flights and 3 PASE flights, volatility analysis is restricted to these three temperatures. For some of the flights concentration determinations at these three temperatures required

Fig. 4 Volatility measurements for one RICO (a) and one PASE (b) flight. (a) January 12, 2005 (RF13). (b) September 22, 2007 (RF11)
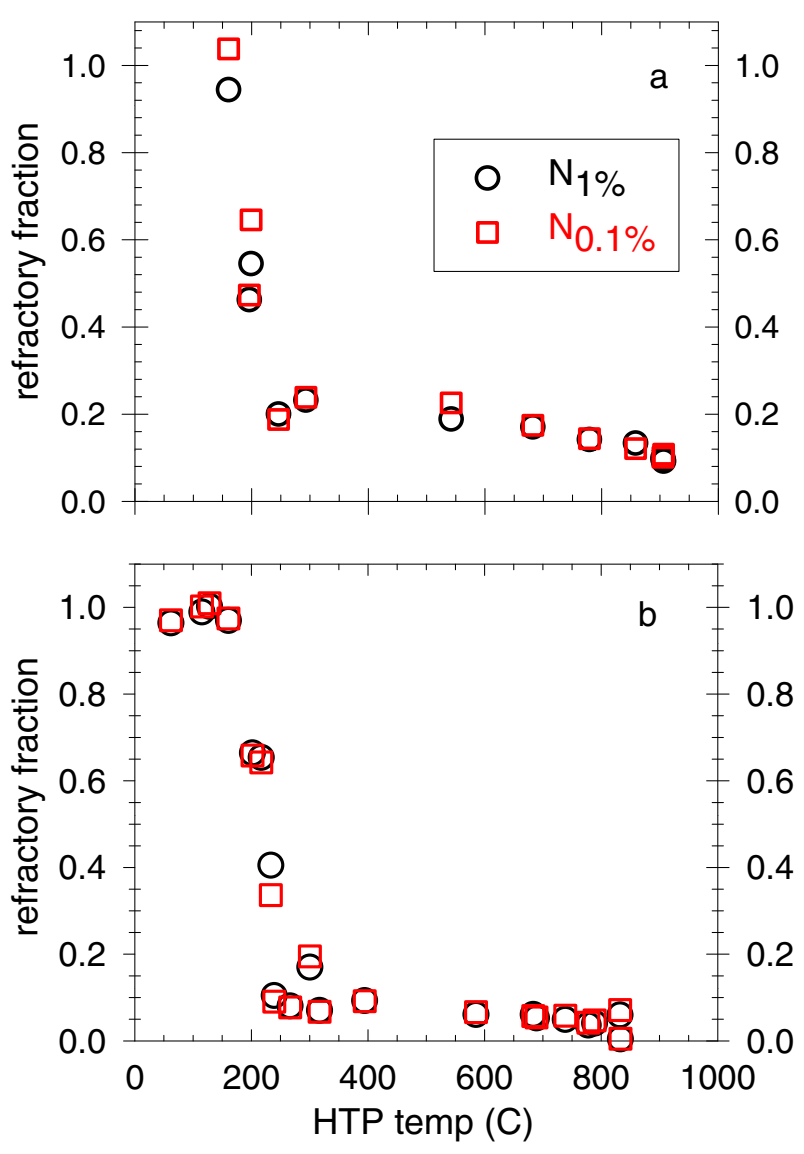
interpolations between measurements at adjacent temperatures. Figure 5 displays plots of the average refractory fractions (surviving or HTP $\mathrm{N}_{\mathrm{CCN}}$ divided by the average of adjacent ambient $\mathrm{N}_{\mathrm{CCN}}$ ) (panel a), refractory concentrations (panel b), and volatile concentrations (difference between ambient and HTP $\mathrm{N}_{\mathrm{CCN}}$ ) (panel c) for $\mathrm{N}_{0.2 \%}$ at $300 \mathrm{C}$ for each flight as a function of average $\mathrm{U}$. An additional plot (panel d) shows how the average ambient $\mathrm{N}_{0.2 \%}$ varied with U. Figure 5 is typical of RICO in that the refractory $\mathrm{N}_{\mathrm{CCN}}$ showed high $\mathrm{R}$ with $\mathrm{U}$ while the volatile $\mathrm{N}_{\mathrm{CCN}}$ were uncorrelated with $\mathrm{U}$ and the ambient $\mathrm{N}_{\mathrm{CCN}}$ were weakly correlated with U. Table 2 displays all of these R values for RICO, which shows consistency of each column of R values for all $\mathrm{S}$ and for each HTP temperature. There is no point in plotting or presenting the volatile fractions since those numbers are always the complement of the refractory fractions with respect to 1.0. They would then necessarily indicate a negative $R$ with respect to $U$ but that would be meaningless. Figure $5 \mathrm{c}$ and column 4 of Table 2 show that the volatile $\mathrm{N}_{\mathrm{CCN}}$ are by no means negatively correlated with $\mathrm{U}$, but are consistently uncorrelated with $\mathrm{U}$. Furthermore, in all cases the volatile $\mathrm{N}_{\mathrm{CCN}}$

Fig. 5 Relationships between average boundary layer $\mathrm{N}_{\mathrm{CCN}}$ at $0.2 \% \mathrm{~S}\left(\mathrm{~N}_{0.2 \%}\right)$ with average $\mathrm{U}$ for 10 RICO flights with volatility measurements at $300 \mathrm{C}$ for (a) refractory fractions, (b) refractory concentrations, (c) volatile concentrations, and (d) ambient $\mathrm{N}_{0.2 \%}$. Flight numbers are plotted as the data points. Linear regressions are displayed
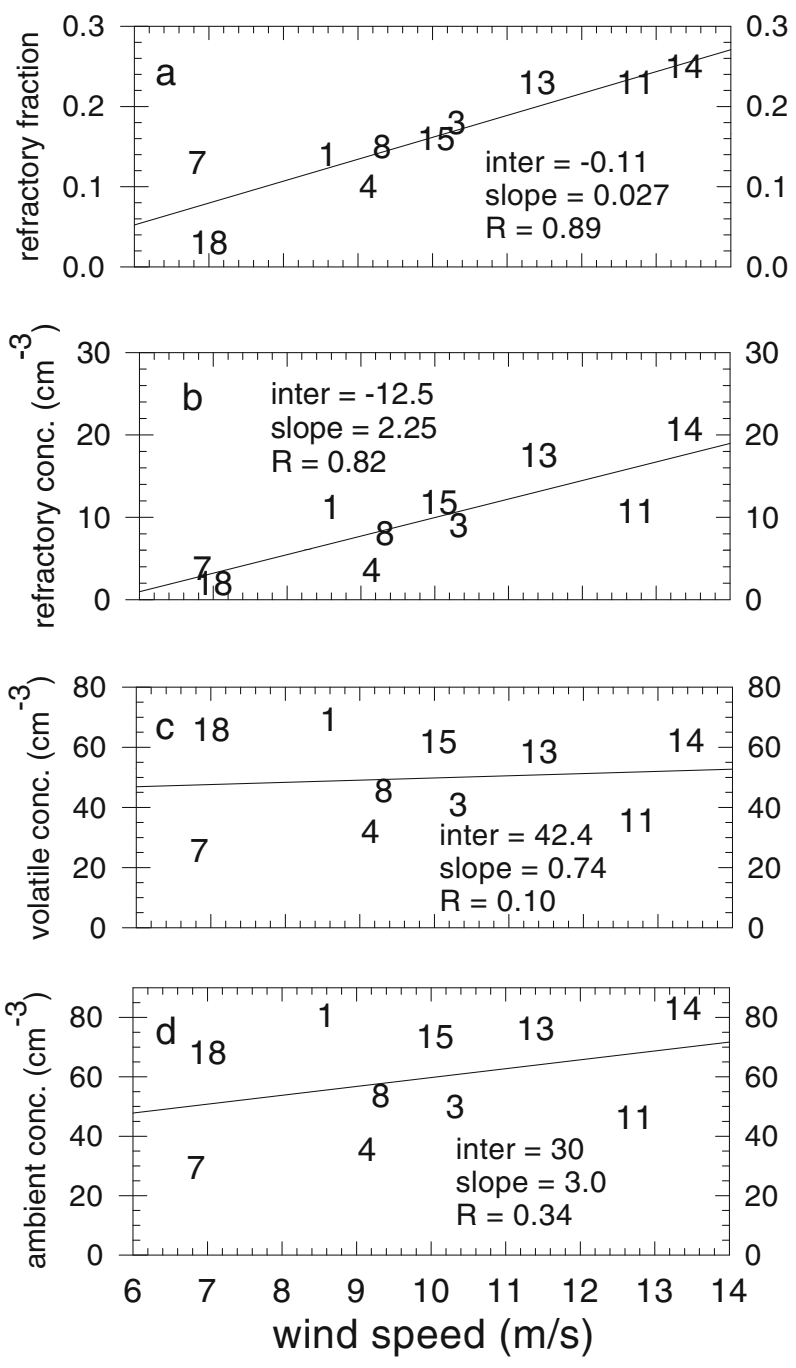
Table 2 Correlation coefficients (R) for RICO of the title quantities (refractory fractions, refractory concentrations, volatile concentrations, and ambient concentrations) with wind speed for cumulative $\mathrm{N}_{\mathrm{CCN}}$ at the supersaturations (S) denoted in the first column and for the 3 HTP temperatures

\begin{tabular}{lllll}
\hline $\mathrm{S}$ & ref & ref & vol & amb \\
& fract & conc & conc & conc \\
\hline
\end{tabular}

$300 \mathrm{C}$

\begin{tabular}{|c|c|c|c|c|}
\hline $1.50 \%$ & 0.68 & 0.48 & -0.11 & 0.09 \\
\hline $1.00 \%$ & 0.77 & 0.64 & -0.06 & 0.11 \\
\hline $0.60 \%$ & 0.69 & 0.53 & 0.03 & 0.22 \\
\hline $0.40 \%$ & 0.76 & 0.71 & 0.15 & 0.33 \\
\hline $0.30 \%$ & 0.82 & 0.73 & 0.15 & 0.35 \\
\hline $0.20 \%$ & 0.89 & 0.82 & 0.10 & 0.34 \\
\hline $0.10 \%$ & 0.89 & 0.78 & -0.03 & 0.25 \\
\hline $0.08 \%$ & 0.70 & 0.74 & 0.15 & 0.22 \\
\hline $0.06 \%$ & 0.88 & 0.75 & -0.12 & 0.21 \\
\hline $0.04 \%$ & 0.81 & 0.67 & -0.06 & 0.22 \\
\hline \multicolumn{5}{|l|}{$400 \mathrm{C}$} \\
\hline $1.50 \%$ & 0.67 & 0.57 & -0.22 & -0.05 \\
\hline $1.00 \%$ & 0.77 & 0.63 & -0.20 & -0.01 \\
\hline $0.60 \%$ & 0.72 & 0.67 & -0.08 & 0.10 \\
\hline $0.40 \%$ & 0.78 & 0.69 & 0.04 & 0.24 \\
\hline $0.30 \%$ & 0.72 & 0.68 & 0.10 & 0.30 \\
\hline $0.20 \%$ & 0.86 & 0.81 & 0.01 & 0.33 \\
\hline $0.10 \%$ & 0.82 & 0.84 & 0.03 & 0.29 \\
\hline $0.08 \%$ & 0.83 & 0.84 & -0.02 & 0.27 \\
\hline $0.06 \%$ & 0.54 & 0.66 & -0.09 & 0.26 \\
\hline $0.04 \%$ & 0.93 & 0.86 & -0.10 & 0.28 \\
\hline \multicolumn{5}{|l|}{$500 \mathrm{C}$} \\
\hline $1.50 \%$ & 0.69 & 0.66 & -0.11 & 0.04 \\
\hline $1.00 \%$ & 0.57 & 0.55 & -0.07 & 0.07 \\
\hline $0.60 \%$ & 0.74 & 0.77 & 0.01 & 0.18 \\
\hline $0.40 \%$ & 0.63 & 0.69 & 0.14 & 0.30 \\
\hline $0.30 \%$ & 0.75 & 0.75 & 0.16 & 0.33 \\
\hline $0.20 \%$ & 0.83 & 0.80 & 0.12 & 0.32 \\
\hline $0.10 \%$ & 0.91 & 0.85 & -0.03 & 0.23 \\
\hline $0.08 \%$ & 0.79 & 0.84 & -0.10 & 0.20 \\
\hline $0.06 \%$ & 0.71 & 0.81 & -0.14 & 0.18 \\
\hline $0.04 \%$ & 0.89 & 0.94 & -0.17 & 0.21 \\
\hline
\end{tabular}

have lower $R$ with $U$ than the ambient $\mathrm{N}_{\mathrm{CCN}}$ with $\mathrm{U}$. Since ambient $\mathrm{N}_{\mathrm{CCN}}$ are the sums of the volatile and refractory $\mathrm{N}_{\mathrm{CCN}}$ their small positive $\mathrm{R}$ with $\mathrm{U}$ are due to the high $\mathrm{R}$ for refractory $\mathrm{N}_{\mathrm{CCN}}$ and low $\mathrm{R}$ for volatile $\mathrm{N}_{\mathrm{CCN}}$ and that volatile $\mathrm{N}_{\mathrm{CCN}}$ is greater than refractory $\mathrm{N}_{\mathrm{CCN}}$.

Figure 6a displays the slopes of the linear regressions of the refractory fractions with $\mathrm{U}$ (i.e., Fig. 5a is one example) as a function of S for the 3 HTP temperatures for RICO. This shows how refractory $\mathrm{N}_{\mathrm{CCN}}$ at lower $\mathrm{S}$ are more responsive to $\mathrm{U}$; i.e., wind more efficiently produces lower $\mathrm{S} \mathrm{N}_{\mathrm{CCN}}$ (larger particles). Figure $6 \mathrm{~b}-\mathrm{d}$ display the predictions of refractory fractions based on the various linear regressions of the measured relationships between refractive fractions and $U$ (again Fig. 5a is one example) at three specified wind speeds. The higher wind 
Fig. 6 All for RICO. (a) Slopes of the linear regressions of refractory fractions of $\mathrm{N}_{\mathrm{CCN}}$ versus $U$ for various $S$ for three HTP temperatures. (b-d) Predictions of refractory fractions at various $\mathrm{S}$ and $\mathrm{HTP}$ at the denoted $U$ values derived from the linear regressions between measured refractive fractions and $\mathrm{U}$ such as Fig. 5a
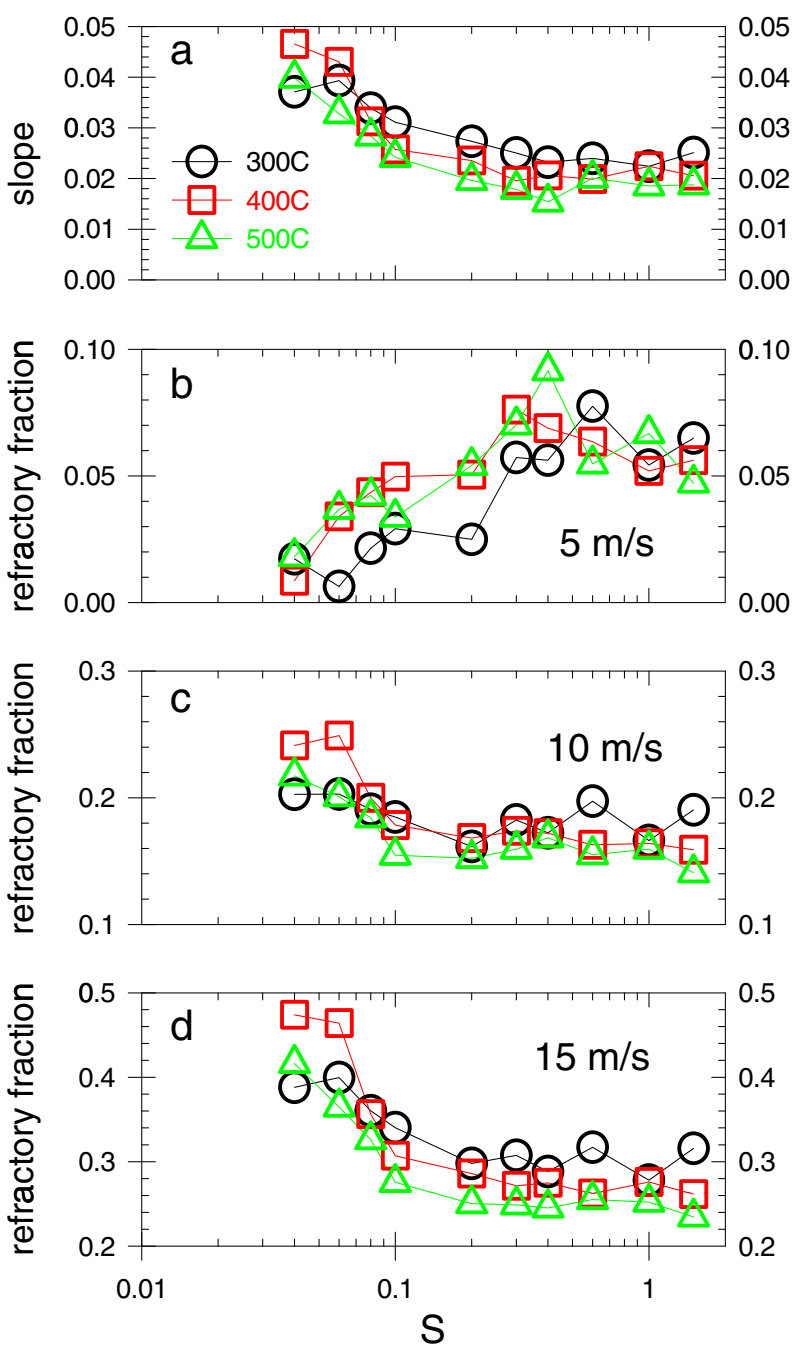

speeds recapitulate the more efficient production of lower $\mathrm{S} \mathrm{N}_{\mathrm{CCN}}$ displayed in Fig. 6a. In Fig. $6 \mathrm{~b}$ the extremely low refractory fractions especially the fact that these are lower for low $\mathrm{S}$ shows that these predictions for low wind speeds are not realistic because there is very little mechanical aerosol production at such low wind speeds (e.g., O'Dowd et al. 1997).

Figure 7a displays the consistency with $\mathrm{S}$ of the four $\mathrm{R}$ columns of Table 2, i.e., the consistently high $\mathrm{R}$ values for refractory $\mathrm{N}_{\mathrm{CCN}}$ with $\mathrm{U}$, and the consistent non correlation with $\mathrm{U}$ of the volatile and ambient $\mathrm{N}_{\mathrm{CCN}}$. Figure $7 \mathrm{~b}$ and Table 3 show lower and less consistent $\mathrm{R}$ values for PASE. At least for the higher $\mathrm{S}$ values the refractory $\mathrm{R}$ values are higher than the volatile $\mathrm{R}$ values as is the case for RICO. At lower $\mathrm{S}$ the relative correlation patterns are inconsistent for PASE. Figure 8 shows that the trends in Fig. 7 are similar when higher volatility temperatures are considered. Again Fig. $8 \mathrm{~b}$ displays the lower R values for refractory in PASE compared to RICO and the smaller contrast between refractory and volatile $\mathrm{R}$ values with $\mathrm{U}$ than RICO. Figure $8 \mathrm{~b}$ shows a more consistent difference between refractory and volatile than Fig. $7 \mathrm{~b}$. The lower R values for $500 \mathrm{C}$ in Fig. $8 \mathrm{~b}$ are probably 
Fig. $7 \mathrm{R}$ between the $\mathrm{CCN}$ quantities designated in the legend with $U$ as a function of $S$ for 300C HTP for (a) RICO and (b) PASE. Figures for 400 and $500 \mathrm{C}$ are nearly identical

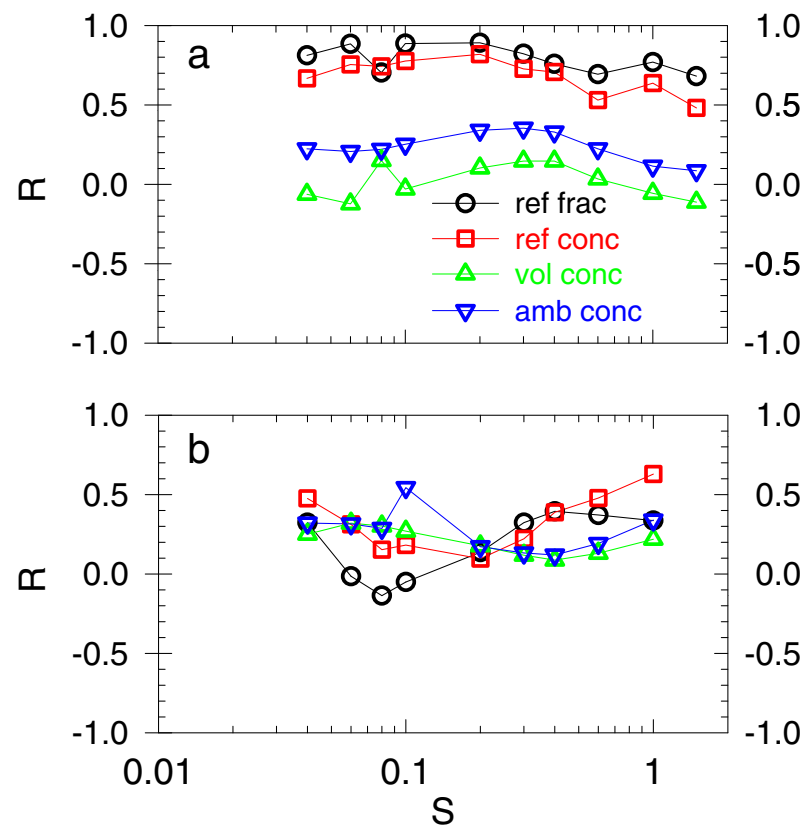

due to the smaller number of data points, only 6 points compared to 8 for 300 and 400C. Figures 7 and 8 consistently show that refractory $\mathrm{N}_{\mathrm{CCN}}$ are related to $\mathrm{U}$ while volatile $\mathrm{N}_{\mathrm{CCN}}$ are not related to U. This is more so for RICO than PASE.

Figure 9 displays the contrast between average boundary layer $\mathrm{CCN}$ spectra measured for the RICO flight with the highest boundary layer average U with CCN spectra measured in a RICO flight with one of the lowest boundary layer average U. The rather similar ambient spectra in the two panels of Fig. 9 contrasts with the much higher refractory concentrations of panel a compared with panel $\mathrm{b}$ at all $\mathrm{S}$. The shallower slope of the refractory compared to the ambient spectra in panel a contrasts with the similar slopes of the ambient and refractory of panel $b$. There is also a noticeably larger difference between the ambient and volatile concentrations for panel a compared to the imperceptible difference of these two spectra in panel b. Figure 9 thus demonstrates a specific example of the production of CCN, especially low S CCN, by the mechanical action of wind on the sea surface. The $\mathrm{R}$ for refractory $\mathrm{N}_{\mathrm{CCN}}$ with $\mathrm{U}$ (i.e., as Fig. 5a) are not high enough for PASE to produce feasible representative comparisons or a PASE figure such as Fig. 6.

Figure 10 displays the ratios of the three average boundary layer $\mathrm{CCN}$ spectra for the two projects. First this shows the much higher mean ambient concentrations of PASE. The ambient ratio at $1 \% \mathrm{~S}$ is slightly less for these flights with volatility data than the factor of 3 difference for all flights shown in Table 1 . The contrast of $\mathrm{N}_{\mathrm{CCN}}$ at all $\mathrm{S}$ between the projects was consistent throughout each project in spite of the more remote location of PASE compared to RICO. The contrast between the two panels of Fig. 10 shows that most of the difference in $\mathrm{N}_{\mathrm{CCN}}$ is due to the difference in volatile $\mathrm{CCN}$ rather than refractory $\mathrm{CCN}$ although refractory $\mathrm{N}_{\mathrm{CCN}}$ is also higher in PASE than RICO. The refractory $\mathrm{N}_{\mathrm{CCN}}$ ratios between PASE and RICO are rather constant with S except for the lowest $\mathrm{S}$ whereas the ambient and volatile ratios progressively increase with all lower $\mathrm{S}$ except some intermediate $\mathrm{S}$ for $500 \mathrm{C}$. The difference in ambient $\mathrm{N}_{\mathrm{CCN}}$ between the two projects is thus dominated by the differences in volatile $\mathrm{N}_{\mathrm{CCN}}$ rather than the differences in refractory $\mathrm{N}_{\mathrm{CCN}}$. 
Table 3 As Table 2 but for PASE

\begin{tabular}{lllll}
\hline $\mathrm{S}$ & ref & ref & vol & amb \\
& fract & conc & conc & conc \\
\hline
\end{tabular}

$300 \mathrm{C}$

$\begin{array}{lrllr}1.00 \% & 0.34 & 0.63 & 0.22 & 0.34 \\ 0.60 \% & 0.37 & 0.48 & 0.13 & 0.19 \\ 0.40 \% & 0.39 & 0.39 & 0.09 & 0.12 \\ 0.30 \% & 0.32 & 0.22 & 0.12 & 0.13 \\ 0.20 \% & 0.14 & 0.010 & 0.18 & 0.17 \\ 0.10 \% & -0.05 & 0.18 & 0.27 & 0.54 \\ 0.08 \% & -0.14 & 0.15 & 0.30 & 0.29 \\ 0.06 \% & -0.01 & 0.31 & 0.32 & -0.59 \\ 0.04 \% & 0.32 & 0.48 & 0.25 & 0.32 \\ 400 \mathrm{C} & & & & \end{array}$

\begin{tabular}{lrrrr}
$1.00 \%$ & 0.51 & 0.66 & 0.23 & 0.34 \\
$0.60 \%$ & 0.42 & 0.48 & 0.14 & 0.19 \\
$0.40 \%$ & 0.48 & 0.40 & 0.08 & 0.12 \\
$0.30 \%$ & 0.35 & 0.21 & 0.12 & 0.13 \\
$0.20 \%$ & 0.26 & 0.11 & 0.17 & 0.17 \\
$0.10 \%$ & -0.07 & 0.05 & 0.28 & 0.54 \\
$0.08 \%$ & 0.21 & 0.30 & 0.28 & 0.29 \\
$0.06 \%$ & 0.11 & 0.34 & 0.31 & -0.59 \\
$0.04 \%$ & 0.51 & 0.53 & 0.23 & 0.32 \\
$500 \mathrm{C}$ & & & & \\
$1.00 \%$ & 0.33 & 0.13 & -0.15 & -0.12 \\
$0.60 \%$ & 0.27 & -0.09 & -0.34 & -0.32 \\
$0.40 \%$ & 0.28 & -0.27 & -0.48 & -0.46 \\
$0.30 \%$ & 0.17 & -0.34 & -0.52 & -0.51 \\
$0.20 \%$ & 0.17 & -0.39 & -0.55 & -0.54 \\
$0.10 \%$ & -0.19 & -0.47 & -0.59 & -0.58 \\
$0.08 \%$ & -0.21 & -0.47 & -0.60 & -0.59 \\
$0.06 \%$ & -0.40 & -0.51 & -0.60 & -0.59 \\
$0.04 \%$ & -0.49 & -0.55 & -0.63 & -0.62 \\
\hline
\end{tabular}

\section{Discussion}

The volatility results from RICO clearly show that significant numbers of CCN are produced by wind action at the sea surface. The refractory fractions in the clean air masses of RICO (50-200 $\mathrm{cm}^{-3}$ for $\mathrm{N}_{1 \%}$ [H9]; average $106 \mathrm{~cm}^{-3}$ [Table 1]) were $0.20-0.35$ for $\mathrm{U}$ approaching $15 \mathrm{~m} / \mathrm{s}$ for $\mathrm{S} 0.1-1 \%$ and $0.35-0.50$ for $\mathrm{S}<0.1 \%$ (Fig. 6). At $10 \mathrm{~m} / \mathrm{s}$ the refractory fraction was $0.14-0.20$ for $\mathrm{S}>0.1 \%$ and $0.15-0.25$ for lower $\mathrm{S} \mathrm{N}_{\mathrm{CCN}}$. For $\mathrm{U}$ less than $7 \mathrm{~m} / \mathrm{s}$ the refractory fractions were less than 0.15 .

Volatility results from PASE are less conclusive. Although refractory $\mathrm{N}_{\mathrm{CCN}}$ were usually positively correlated with $\mathrm{U}$, the $\mathrm{R}$ values are so low that regression equations should not be used to predict refractory $\mathrm{N}_{\mathrm{CCN}}$ as is the case for RICO (i.e., Fig. 6c and d). Nevertheless, the relatively lower $R$ for volatile and ambient $\mathrm{N}_{\mathrm{CCN}}$ with $\mathrm{U}$ compared to refractory with $U$ indicates some influence of $U$ on refractory $N_{C C N}$. The higher refractory 
Fig. $8 \mathrm{R}$ between $\mathrm{N}_{1 \%}$ and $\mathrm{U}$ for the various quantities designated in the legend as a function of HTP temperature for (a) RICO and (b) PASE. Figures for all measured $\mathrm{S}$ are similar
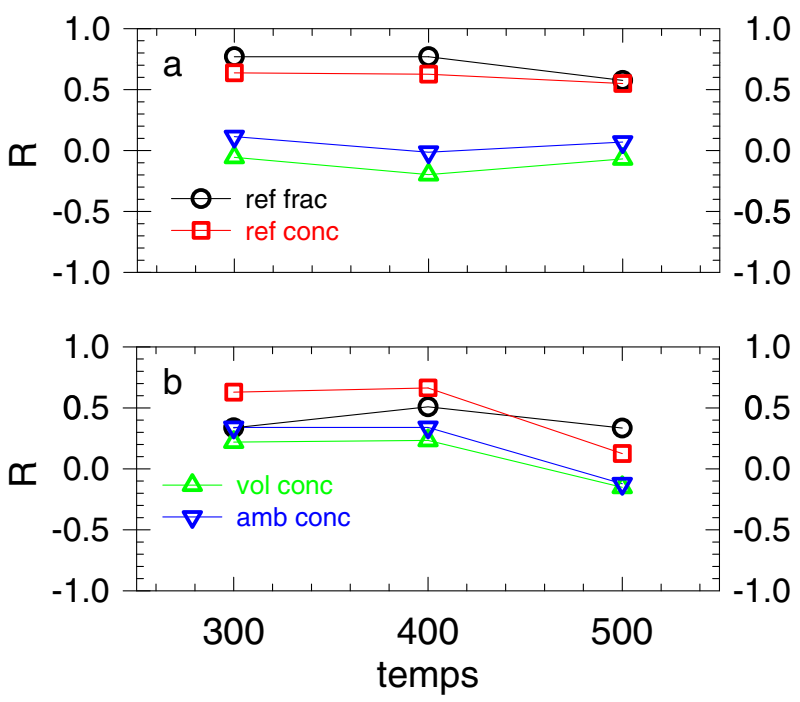

$\mathrm{N}_{\mathrm{CCN}}$ of PASE compared to RICO (Fig. 10a) may seem incompatible with the lower R for refractory $\mathrm{N}_{\mathrm{CCN}}$ with $\mathrm{U}$ in PASE, but this is probably due to one of the phenomena that yields the higher ambient $\mathrm{N}_{\mathrm{CCN}}$ in PASE - the lack of clouds compared to RICO (HN9). Other possible reasons for this difference include greater DMS emissions and long range transport of higher concentrations in PASE (Gray et al. 2010). The consistently high

Fig. 9 RICO average ambient, refractory, and volatile boundary layer CCN spectra with respect to 500C for (a) January 14 with average $U$ of $13.4 \mathrm{~m} / \mathrm{s}$ and (b) January 23 with average $U$ of $7.1 \mathrm{~m} / \mathrm{s}$
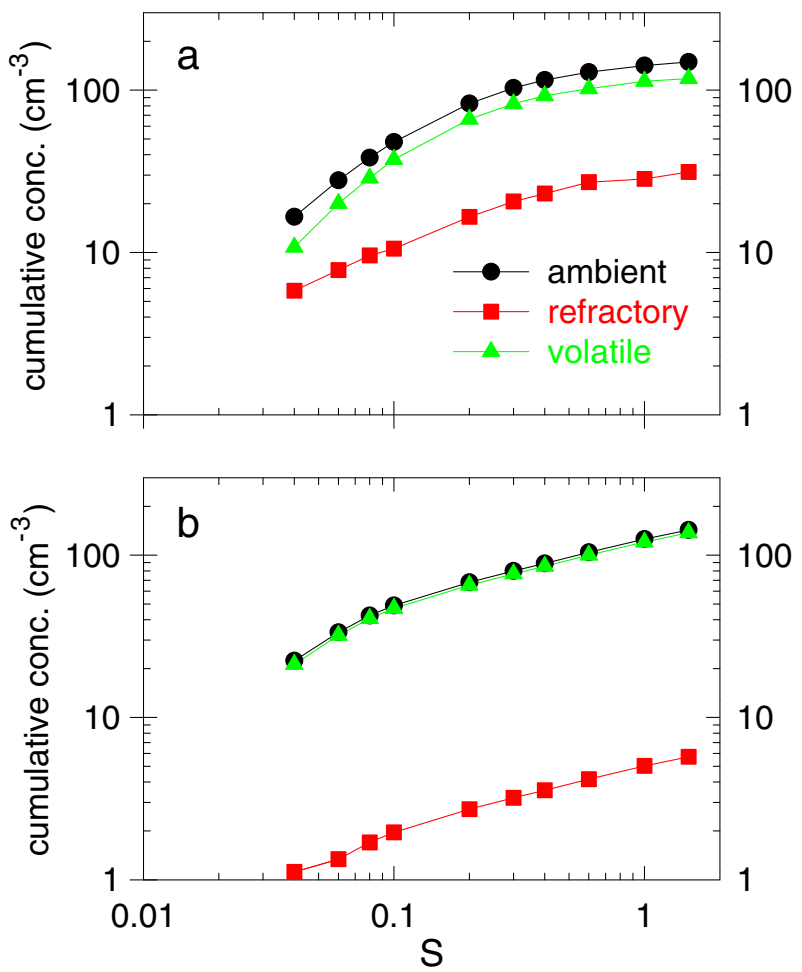
Fig. 10 Ratios of average $\mathrm{N}_{\mathrm{CCN}}$ of PASE to RICO for ambient and refractory (a) and volatile (b) at the three HTP temperatures

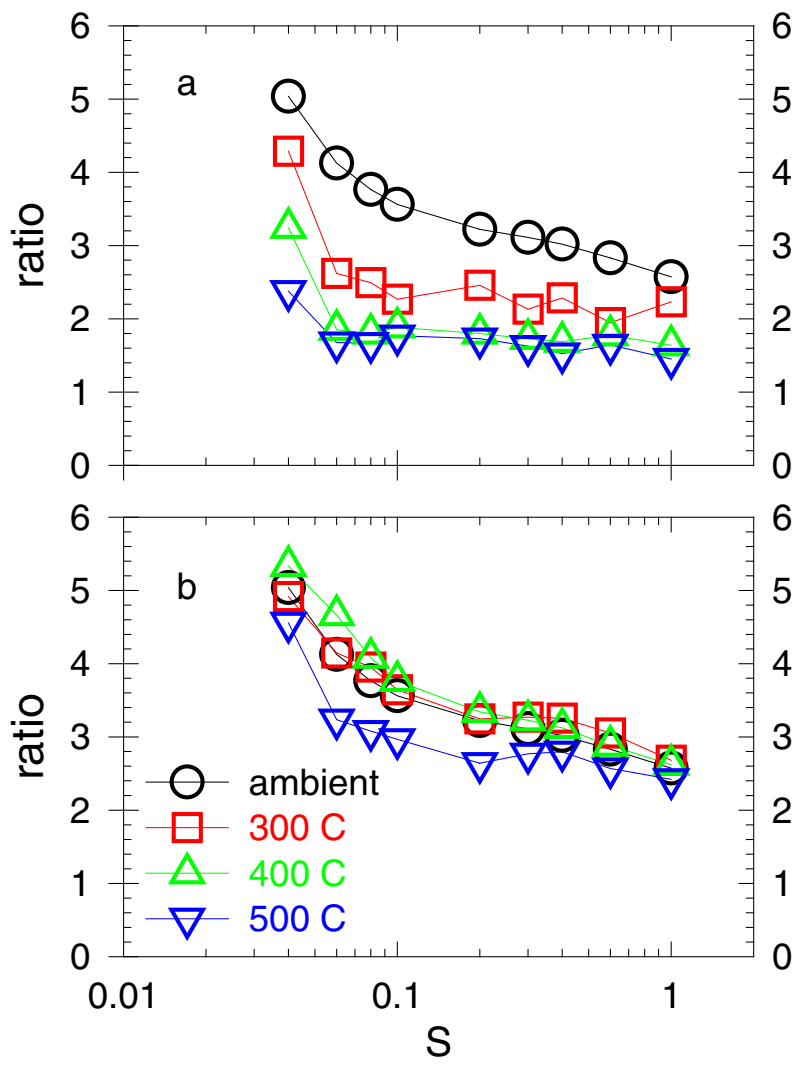

$\mathrm{N}_{\mathrm{CCN}}$ throughout PASE probably made new particle formation unlikely, especially given the rather similar $\mathrm{CN}$ and $\mathrm{CCN}$ concentrations (HN9). Production by DMS was more likely manifested in increases in particle size due to condensation of material onto existing particles.

PASE was conducted in an area and time period of minimal cloudiness. Gray et al. (2010) showed that clouds were present for only 2-3\% of the PASE flight tracks whereas this range for RICO was $1-40 \%$ (H9). Moreover, the PASE clouds were very shallow (seldom more than 100 m thick; HN9) whereas the RICO clouds were hundreds of $\mathrm{m}$ to a few km thick (H9). This produced much larger liquid water contents (LWC), droplet sizes and drizzle concentrations in RICO. Vertical velocities were also higher in RICO than PASE (HN9). Furthermore, the reason for most of the non-flight days in RICO was too many clouds, which meant that there was even more cloud scavenging of aerosol between many of the RICO flights. Too many clouds was not a reason for non-flight days during PASE. Variations in cloudiness was probably the reason for the much greater than expected variability of $\mathrm{N}_{\mathrm{CCN}}$ and $\mathrm{N}_{\mathrm{c}}$ among the RICO flights, a factor of 4 for both (H9), which is twice the factor of 2 range of variability of these quantities in PASE (HN9). Less cloud scavenging in PASE provided longer atmospheric residence times for particles, especially smaller particles, which have lower fall speeds that less readily deposit them to the surface. Thus, clouds are an efficient removal pathway for small particles, which have low fall speeds. Cloud removal is obvious for CCN but it is also the case for particles too small or too insoluble to be CCN. These cloud interstitial particles are efficiently coagulated with the 
large surface areas provided by cloud droplets (Twomey 1977), especially if they are small and thus more Brownian mobile.

The lack of clouds in PASE allowed particle concentrations from all sources to build up whereas the clouds of RICO reduced all particle concentrations, but especially the concentrations of smaller particles. Shorter atmospheric residence times of particles that is provided by the presence of clouds then tend to more closely couple particle concentrations to their sources, which for refractory particles is the immediate U. This is why Fig. 1 shows high $\mathrm{R}$ with $\mathrm{U}$ for particles as small as $0.2 \mu \mathrm{m}$ in RICO but high $\mathrm{R}$ with $\mathrm{U}$ only for particles larger than $9 \mu \mathrm{m}$ in PASE.

The concentrations of larger particles, on the other hand, can be enhanced by cloud scavenging because many if not most cloud droplets evaporate, thus leaving behind larger particles than the nuclei they originally condensed upon. This enhancement of dry and ambient particle sizes is due to coalescence of multiple cloud droplets, Brownian capture of cloud interstitial particles, and gas to particle reactions within droplets. This is probably the reason for higher average FSSP concentrations in RICO compared to PASE for sizes larger than $5 \mu \mathrm{m}$. This difference progressively increased with particle size. Although some of this difference may be due to slightly higher $\mathrm{U}$ and RH of RICO (Table 1), since this is such a large contrast to the immense opposite average concentration differences at smaller sizes (i. e., Table 1 and Fig. 10), the concentration differences at large sizes are probably mostly a result of the cloud processes that have been mentioned.

The closer coupling of intermediate sized particle concentrations with $U$ in RICO provided by the shorter residence times of these particles due to more cloud scavenging provided the higher $\mathrm{R}$ for $\mathrm{N}_{\mathrm{CCN}}$ with $\mathrm{U}$ for RICO than PASE as reflected in Tables 2 and 3 and Figs. 7 and 8. In other words the longer residence times of the particles in PASE meant that refractory concentrations were more dependent on $U$ at earlier times and at different locations than the $U$ measurements simultaneous with the particle measurements. The simultaneously measured $U$ in PASE was related only to particles larger than $9 \mu \mathrm{m}$ (Fig. 1b), which have very short residence times due to their large fall velocities with or without clouds.

A major difference between the two projects is the much greater volatile fractions and volatile concentrations in PASE, especially out to so much larger sizes than RICO. Figure 1a indicates that most particles larger than $0.2 \mu \mathrm{m}$ are refractory so that volatile particles in RICO were restricted to smaller sizes than in PASE where they seem to extend up to $9 \mu \mathrm{m}$ (Fig. 1b); yet most of the CCN, some of which are refractory, are smaller. The main reason that particles in the $0.2-9 \mu \mathrm{m}$ size range were not related to U in PASE is that many more of these particles were derived from other sources than the sea surface wind and like most of the CCN they are probably volatile and most likely sulfates of natural or anthropogenic origin. In RICO these particle concentrations were lower probably because of cloud scavenging processes, which thus left mostly only the refractory sea salt particles that are continuously produced by wind within this size range (above $0.2 \mu \mathrm{m}$ ). Another reason for the lack of refractory $\mathrm{N}_{\mathrm{CCN}}$ correlations with $\mathrm{U}$ in PASE is the smaller refractory fractions compared to RICO (e.g., Figs. 4 and 10), which thus decreased the precision and accuracy of the refractory determinations relative to ambient concentrations in PASE. Thus, the $R$ values of PASE refractory $\mathrm{N}_{\mathrm{CCN}}$ with $\mathrm{U}$ might really be higher than those that are presented. Though, as mentioned earlier, these concentrations are probably also related to winds at different locations and times.

There was probably more of a dichotomy of particle sizes in RICO with respect to their compositions whereas PASE was probably more mixed in composition with respect to size. The high $\mathrm{R}$ for particles in the $0.2-9 \mu \mathrm{m}$ range (and larger) with $\mathrm{U}$ in RICO indicates 
dominance of refractory wind derived particles over all of this size range. The low $\mathrm{R}$ for this same particle size range with $U$ in PASE indicates dominance of particles with origins other than wind at the ocean surface. Yet given the similar average $U$ of the two projects (Table 1) there must still be the same production of refractory particles by wind in PASE that is so easily observed in RICO. And indeed the higher refractory $\mathrm{N}_{\mathrm{CCN}}$ concentrations of PASE seem to attest to this fact. But in this size range in PASE there are enough CCN of other origins to thwart $\mathrm{N}_{\mathrm{CCN}}-\mathrm{U}$ correlations. These are probably more volatile; i.e., sulfates of natural or anthropogenic origin. The size range of most CCN barely extends into the PCASP range; the dry size of a $0.04 \% \mathrm{~S} \mathrm{CCN}$ is $0.19-0.24 \mu \mathrm{m}$ for $\mathrm{NaCl}$-ammonium sulfate respectively. The equilibrium sizes of such particles at the ambient $\mathrm{RH}$ of these projects are approximately $0.35-0.44 \mu \mathrm{m}$. For $0.1 \% \mathrm{~S}$ this ambient size would be $0.19-0.24 \mu \mathrm{m}$ whereas for $1 \% \mathrm{~S}$ these sizes would be $0.04-0.05 \mu \mathrm{m}$ diameter. Thus, the $\mathrm{CCN}$ size range is also a size range of rapidly changing efficiency of wind produced sea salt with respect to size (Jennings and O'Dowd 1990 [hereafter JO0]; OS3). This is apparent upon close examination of Fig. 7a; i.e., higher $\mathrm{R}$ for lower $\mathrm{S} \mathrm{N}_{\mathrm{CCN}}$ with $\mathrm{U}$ in RICO. Figure 1 also attests to the fact that much smaller particles are related to U in RICO compared to PASE where much larger particles are well correlated with $\mathrm{N}_{\mathrm{CCN}}$ but not with $U$ (up to $9 \mu \mathrm{m}$ ). The much larger volatile particles of PASE may also be enhanced by the condensation of the $\mathrm{SO}_{2}$ produced by DMS emissions from the ocean. Although the high particle concentrations, and thus large surface areas, in PASE may have precluded the nucleation of new particles, which was a major goal of PASE, the DMS/SO2 condensation may very well have enhanced particle sizes (Sievering et al. 2004; Faloona et al. 2010).

In general there were 2.5-5 times more volatile (probably mostly sulfate type particles) $\mathrm{N}_{\mathrm{CCN}}$ in PASE compared to RICO whereas there were only 1.5-4 times as many refractory (sea salt) $\mathrm{N}_{\mathrm{CCN}}$ (Fig. 10). Figure 4 and the other four RICO and two PASE flights with HTP measurements above $500 \mathrm{C}$ display the somewhat perplexing observation that significant refractory concentrations persisted to temperatures beyond $800 \mathrm{C}$. This suggests that some of the refractory $\mathrm{CCN}$ may not be $\mathrm{NaCl}$ but substances with even higher thermal fractionation temperatures. Some of these may be sodium sulfate, which has a thermal fractionation temperature nearly $100 \mathrm{C}$ higher than $\mathrm{NaCl}$ or they may be carbon soot, which has a similarly high fractionation temperature. JO0 and $\mathrm{O} 3$ made similar observations and made similar attributions. Since sodium sulfate is a conversion of $\mathrm{NaCl}$ the concentrations of sodium sulfate particles should still be related to $U$ though perhaps not to the immediate simultaneous $U$ due to possible delay in this conversion. Carbon soot is not expected to be related to sea surface particle production.

\section{Concluding remarks}

This study suggests that sea salt production by wind at the ocean surface is a more significant source of CCN than indicated by Twomey (1971); Charlson et al. (1987) or HD6, but less significant than Dinger et al. (1970); Murphy et al. (1998), JO0 or OS3. This was the first study to combine actual CCN measurements and especially CCN spectra with wind speed measurements. The different results compared to the earlier studies are probably due to the fact that the first four did not include wind measurements or wind considerations and they did not include CCN spectra or, for the first two studies, specification of the $\mathrm{S}$ values for the $\mathrm{N}_{\mathrm{CCN}}$. The other three studies in the first sentence of this paragraph did not include actual CCN measurements but used particle size measurements. Nevertheless, the present study largely agrees with JO0 and OS3. Comparisons among projects are hampered 
by the different altitudes of the wind speed measurements; $10 \mathrm{~m}$ for JO0 and OS3. The fact that volatile $\mathrm{N}_{\mathrm{CCN}}$ were uncorrelated with wind speed (U) agrees with OS3 that the ocean was not stirred enough by wind to increase DMS emissions and thus increase sulfate aerosol.

All of the previous considerations of the impact of wind driven $\mathrm{CCN}$ on clouds (especially and specifically all papers referenced herein) assumed that the only $\mathrm{CCN}$ relevant to maritime clouds, which are the most important clouds for global climate, are those with supersaturations (S) $<0.2$ or $0.3 \%$ because it was assumed that the more predominant stratus clouds with their lower vertical wind speeds seldom achieve $\mathrm{S}$ of more than $0.1-0.3 \%$. This restriction leaves out the more numerous higher $\mathrm{S}$ particles that are smaller and dominated by volatile (i.e., sulfate) compositions (JO0; OS3). This left the refractory sea salt $\mathrm{CCN}$ with a much higher fraction of $\mathrm{N}_{\mathrm{CCN}}$ than if higher $\mathrm{S}$ values had been considered. Hudson et al. (2010), however, demonstrated by comparisons of CCN spectra below stratus clouds with stratus cloud average $\mathrm{N}_{\mathrm{c}}$ that the $\mathrm{S}$ in clean maritime clouds (i.e., $\mathrm{N}_{1 \%}<200 \mathrm{~cm}^{-3}$ ) are usually considerably higher than $0.3 \%$; they are of order $1 \% \mathrm{~S}$ and often exceed $1 \% \mathrm{~S}$. Stratus cloud S less than $0.3 \%$ was found only for $\mathrm{N}_{1 \%}$ in excess of $300 \mathrm{~cm}^{-3}$. Furthermore, these cloud $\mathrm{S}$ estimates by Hudson et al. (2010) were underestimates of initial cloud $S$ that determines initial $N_{c}$ because the decrease of average $\mathrm{N}_{\mathrm{c}}$ by entrainment was not considered. The higher $\mathrm{S}$ of maritime stratus clouds indicates a smaller role for sea salt $\mathrm{CCN}$ relative to volatile (i.e., sulfate) CCN. Little evidence is found here for significant refractory $\mathrm{N}_{\mathrm{CCN}}$ at high $\mathrm{S}$ that had been suggested by Clarke et al. (2006).

Latham and Smith (1990) had suggested that higher maritime wind speeds brought about by global warming by greenhouse gases might increase $\mathrm{CCN}$ concentrations and thus increase cloud albedo (first IAE) thus adding to the purported counteracting climate effect of IAE (global cooling). This study certainly supports this possibility, but it should be remembered that this same mechanism also produces even more enhancements of particles much larger than CCN, i.e., giant nuclei, which Gerber et al. (2008); Arthur et al. (2010); Reiche and Lasher-Trapp (2010); Hudson et al. (2011) and others have indicated to have a destabilizing effect on cloud microphysics that might thus work in the opposite direction of IAE.

The low percentages of refractory $\mathrm{CCN}$ in PASE indicates a smaller role for sea salt production compared to RICO. However, a major reason for the higher $\mathrm{N}_{\mathrm{CCN}}$ in PASE (fewer clouds) tends to negate the climate impact of these higher $\mathrm{N}_{\mathrm{CCN}}$. Although volatile non-sea salt CCN are much more prominent in PASE and probably in other locations that lack clouds, the lack of clouds makes such regions immune to the climate effects of high $\mathrm{N}_{\mathrm{CCN}}$, except when they are transported to more cloudy regions. However, regions with more clouds provide the cloud scavenging mechanisms that preferentially neutralize high $\mathrm{N}_{\mathrm{CCN}}$, especially in comparison to the continually produced sea salt particles (as long as there is wind $>\sim 4 \mathrm{~m} / \mathrm{s}$; e.g., O'Dowd et al. 1997). Cloud scavenging with respect to the relative role of sea salt $\mathrm{CCN}$ is more pertinent to particles that are transported over long distances (i.e., continental origin, which is more likely anthropogenic) than to particles produced in situ from DMS that may be as spontaneously produced as sea salt. The contrasts between PASE and RICO clearly illustrate the extremes of maritime regions relevant to the important question of $\mathrm{CCN}$ sources. In the end this study indicates that there is a complex interplay among production and removal processes that needs resolution if progress is to be made in climate change research related to atmospheric aerosol (IAE).

Acknowledgements The RICO work was supported by National Science Foundation (NSF) ATM-0342618. The PASE work was supported by NSF ATM-0627227. All measurements were made on board the NCAR C-130 airplane, which is also NSF supported. 
Open Access This article is distributed under the terms of the Creative Commons Attribution Noncommercial License which permits any noncommercial use, distribution, and reproduction in any medium, provided the original author(s) and source are credited.

\section{References}

Alley, R.B., et al.: Summary for policymakers. In: Solomon, S., et al. (eds.) Climate Change 2007: The Physical Science Basis: Contribution of Working Group I to the Fourth Assessment Report of the Intergovernmental Panel on Climate Change, pp. 1-18. Cambridge Univ. Press, New York (2007)

Arthur, D.K., Lasher-Trapp, S., Abdel-Haleem, A., Klosterman, N., Ebert, D.S.: A new three-dimensional visualization system for combing aircraft and radar data and its application to RICO observations. J. Atmos. Ocean. Techn. 27, 811-828 (2010). doi:10.1175/2009JTECHA1395.1

Charlson, R.J., Lovelock, J.E., Andreae, M.O., Warren, S.G.: Oceanic phytoplankton, atmospheric sulfur, cloud albedo and climate. Nature 326, 655-661 (1987)

Clarke, A.D., Owens, S.R., Zhou, J.C.: An ultrafine sea-salt flux from breaking waves: implications for cloud condensation nuclei in the remote marine atmosphere. J. Geophys. Res.-Atmos. 111(D6), D06202 (2006). doi:10.1029/2005JD006565

Colon-Robles, M., Rauber, R.M., Jensen, J.B.: Influence of low-level wind speed on droplet spectra near cloud base in trade wind cumulus. Geophys. Res. Lett. 33, L20814 (2006). doi:10.1029/2006GL027487

Conley, S.A., Faloona, I., Miller, G.H., Lenschow, D.H., Blomquist, B., Bandy, A.: Closing the dimethyl sulfide budget in the tropical marine boundary layer during the Pacific Atmospheric Sulfur Experiment. Atmos. Chem. Phys. 9, 8745-8756 (2009)

Dinger, J.E., Howell, H.B., Wojceichowski, T.A.: On the source and composition of cloud nuclei in a subsident air mass over the North Atlantic. J. Atmos. Sci. 27(5), 791-797 (1970)

Faloona, I., Conley, S.A., Blomquist, B., Clarke, A.D., Kapustin, V., Howell, S., Lenschow, D.H., Bandy, A. R.: Sulfur dioxide in the tropical marine boundary layer: dry deposition and heterogeneous oxidation observed during the Pacific Atmospheric Sulfur Experiment. J. Atmos. Chem. (2010). doi:10.1007/ s10874-010-9155-0

Gerber, H.: Relative humidity parameterizations of the lognormal size distribution of ambient aerosols. In: Wagner, P.E., Vali, G. (eds.) Lecture Notes in Physics, Vol. 309, pp. 237-238. Springer, Berlin (1988)

Gerber, H., Frick, G., Jensen, J.B., Hudson, J.G.: Entrainment, mixing, and microphysics in trade-wind cumulus. J. Met. Soc. Japan 86A, 87-106 (2008)

Gray, B.A., Wang, Y., Gu, D., Bandy, A., Mauldin, L., Clarke, A., Alexander, B., Davis, D.D.: Sources, transport, and sinks of SO2 over the equatorial Pacific during the Pacific Atmospheric Sulfur Experiment. J. Atmos. Chem. (2010). doi:10.1007/s10874-010-9177-7

Hudson, J.G.: An instantaneous CCN spectrometer. J. Atmos. Ocean. Techn. 6, 1055-1065 (1989)

Hudson, J.G., Da, X.: Volatility and size of cloud condensation nuclei. J. Geophys. Res. 101, 4435-4442 (1996)

Hudson, J.G., Mishra, S.: Relationships between $\mathrm{CCN}$ and cloud microphysics variations in clean maritime air. Geophys. Res. Lett. 34, L16804 (2007). doi:10.1029/2007GL030044

Hudson, J.G., Noble, S.: CCN and cloud droplet concentrations at a remote ocean site. Geophys. Res. Let. 36, L13812 (2009). doi:10.1029/2009GL038465

Hudson, J.G., Noble, S., Jha, V., Mishra, S.: Correlations of small cumuli droplet and drizzle drop concentrations with cloud condensation nuclei concentrations. J. Geophys. Res. 114, D05201 (2009). doi:10.1029/2008JD010581

Hudson, J.G., Noble, S., Jha, V.: Stratus cloud supersaturations. Geophys. Res. Lett. 37, L21813 (2010). doi:10.1029/2010GL045197

Hudson, J.G., Jha, V., Noble, S.: Drizzle correlations with giant nuclei. Geophys. Res. Lett. 38, L05808 (2011). doi:10.1029/2010GL046207

Jennings, S.G., O’Dowd, C.D.: Volatility of aerosol at Mace Head, on the west coast of Ireland. J. Geophys. Res. 95, 13937-13948 (1990)

Latham, J., Smith, M.H.: Effect on global warming of wind-dependent aerosol generation at the ocean surface. Nature 347(6291), 372-373 (1990). doi:10.1038/347372a0Letter

Murphy, D.M., Anderson, J.R., Quinn, P.K., McInnes, L.M., Brechtel, F.J., Kreidenweis, S.M., Middlebrook, A.M., Posfai, M., Thomson, D.S., Buseck, P.R.: Influence of sea-salt on aerosol radiative properties in the Southern Ocean marine boundary layer. Nature 392(6671), 62-65 (1998)

O’Dowd, C.D., Smith, M.H.: Physicochemical properties of aerosols over the northeast Atlantic: evidence for wind-speed-related submicron sea-salt aerosol production. J. Geophys. Res. 98(D1), 1137-1149 (1993) 
O’Dowd, C.D., Smith, M.H., Jennings, S.G.: Sub-micron aerosol, radon and soot carbon characteristics over the North East Atlantic. J. Geophys. Res. 98, 1137-1149 (1993)

O’Dowd, C.D., Smith, M.H., Consterdine, I.E., Lowe, J.A.: Marine aerosol, sea salt, and the marine sulpher cycle: a short review. Atmos. Environ. 31, 73-80 (1997)

Pierce, J.R., Adams, P.J.: Global evaluation of CCN formation by direct emission of sea salt and growth of ultrafine sea salt. J. Geophys. Res. 111, D06203 (2006). doi:10.1029/2005JD006186

Rauber, R.M., et al.: Rain in shallow cumulus over the ocean, the RICO campaign. Bulletin, AMS 88, 19121928 (2007)

Reiche, C.H., Lasher-Trapp, S.: The minor importance of giant aerosol to precipitation development within small trade wind cumuli observed during RICO. Atmos. Res. 95(4), 386-399 (2010)

Sievering, H., Cainey, J., Harvey, M., McGregor, J., Nichol, S., Quinn, A.P.: Aerosol non-sea-salt sulfate in the remote marine boundary layer under clear-sky and normal cloudiness conditions: ocean-derived biogenic alkalinity enhances sea-salt sulfate production by ozone oxidation. J. Geophys. Res. 109, D19317 (2004). doi:10.1029/2003JD004315

Twomey, S.: On the composition of cloud nuclei in the northeastern United States. J. Rech. Atmos. 3, 281-285 (1968)

Twomey, S.: The composition of cloud nuclei. J. Atmos. Sci. 28, 377-381 (1971)

Twomey, S.: Atmospheric Aerosols, p. 302. Elsevier, New York (1977)

Woodcock, A.H.: Atmospheric salt particles and raindrops. J. Meteor. 9, 200-212 (1952)

Yoon, Y.J., Brimblecombe, P.: Modeling the contribution of sea salt and dimethyl sulfide derived aerosol to marine CCN. Atmos. Chem. Phys. 2, 17-30 (2002) 